\title{
Effects on perceptual development of visual deprivation during infancy
}

\author{
TERRI L LEWIS, DAPHNE MAURER, AND HENRY P BRENT \\ From the Hospital for Sick Children, Toronto, Canada, and McMaster University, Hamilton, Canada
}

SUMMARY We measured three aspects of vision in children treated for unilateral congenital cataract: visual resolution, the symmetry of optokinetic nystagmus (OKN), and peripheral vision. Good visual resolution was achieved by children who had had the earliest treatment and who had had the normal eye patched close to $50 \%$ of the waking time throughout early childhood. All children treated for unilateral congenital cataract showed a marked asymmetry of OKN regardless of the age of treatment. One child with early treatment who.could be tested with the Goldmann perimeter also showed especially poor sensitivity in the nasal visual field of her aphakic eye. We found no such deficits in the vision of children who had had normal visual experience during early infancy and then later developed cataracts in one or both eyes. The limitations observed in children treated for congenital cataract are similar to those reported in normal human infants, in normal kittens, and in cats which were visually deprived early in life.

Much of what we, know about the effects of visual deprivation comes from studies of cats which had one eye sutured shut during a critical period shortly after birth. Such cats later show limitations in many aspects of vision, including visual resolution, ${ }^{1}$ peripheral vision (reviewed by Maurer and Lewis ${ }^{2}$ ), and the symmetry of optokinetic nystagmus. ${ }^{34}$ These three aspects of vision are also poorly developed in normal kittens ${ }^{58}$ and in normal human infants. ${ }^{9-11}$

We were interested in determining whether monocular deprivation during early infancy affects the development of these abilities in humans as it does in cats. To do so we turned to a population of children who had been born with a dense, central cataract in one eye. (This condition is similar to lid suture in cats because only diffuse light passes through the cataract.) The cataract had been treated surgically by removing the natural lens of the eye, rendering the eye aphakic. The aphakic eye was fitted with a contact lens which restored nearly normal visual input. Parents were then instructed to patch the normal eye $50 \%$ of the waking time. We measured three aspects of vision in these children: visual resolution, the symmetry of optokinetic nystagmus $(\mathrm{OKN})$, and peripheral vision.

Correspondence to T L Lewis, PhD, Department of Psychology, McMaster University, 1280 Main Street West, Hamilton, Ontario, L85 4KI, Canada.

\section{Experiment I. Visual Resolution}

Visual resolution has been tested both in normal kittens and in normal human infants by showing subjects black-and-white stripes of varying width paired with a grey stimulus of the same mean luminance. The width of the smallest stripes chosen over grey provides a measure of visual resolution. Numerous studies have shown that visual resolution is poorly developed at birth both in cats ${ }^{5}$ and in humans. ${ }^{10}$

Adult cats which had been monocularly deprived for a period after birth also show poor visual resolution in the previously deprived eye. The best visual resolution achieved depends on the duration of deprivation such that, the longer the deprivation, the poorer the visual resolution. ${ }^{1}$ However, the visual resolution of the formerly deprived eye can be improved if the normal eye is sewn shut when the deprived eye is opened, ${ }^{\prime}$ a procedure called reversesuturing. The visual resolution of visually deprived cats also depends on the timing of deprivation. Giffin and Mitchell ${ }^{5}$ demonstrated this in cats which were monocularly deprived for 23 days beginning at 42,64 , or 87 days of age. Only the cats which had been monocularly deprived from $\mathbf{4 2}$ days of age failed to recover normal visual resolution in the deprived eye. Thus in cats the effect of deprivation on the develop- 
ment of visual resolution depends on when the deprivation begins, how long it lasts, and whether or not reverse-suturing occurs. The purpose of the first experiment was to determine whether similar principles apply to humans who had been monocularly deprived.

\section{MATERIALS AND METHODS}

We measured the Snellen acuity of 13 children who had been deprived from birth for varying periods of time because of a dense and central congenital cataract in one eye (congenital group). For comparison we measured the Snellen acuity of 30 children who had had normal visual experience until an injury caused a dense central cataract to develop in one eye sometime after the age of 3 years (traumatic group). During the Snellen test the aphakic eyes were corrected optically to focus at infinity.

\section{RESULTS AND DISCUSSION}

Fig. 1 shows the Snellen acuity of the deprived eye for the congenital group plotted as a function of duration of deprivation, that is, the time from birth until the cataract was removed surgically and the aphakic eye fitted with an appropriate contact lens. The two

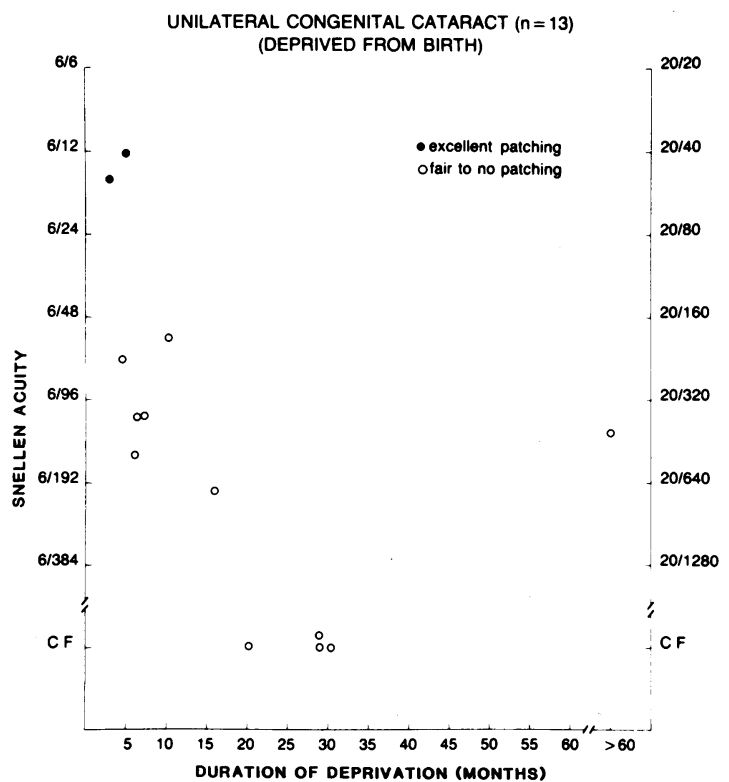

Fig. 1 Snellen acuity as a function of duration of deprivation in the aphakic eye of children treated for unilateral congenital cataract. Snellen acuities are shown in metres on the left axis and in feet on the right axjs. Filled circles represent the results from children who had had the normal eye patched close to $50 \%$ of the waking time throughout early childhood. Open circles represent the results from children who did not. children who had had the shortest periods of deprivation and who had had the normal eye patched close to $50 \%$ of the waking time throughout early childhood had the best Snellen acuities (6/12 and 6/15). The remaining 11 children who had poorer Snellen acuities had had longer periods of deprivation and/or little or no patching of the normal eye.

Fig. 2 shows the Snellen acuity of the deprived eye for the traumatic group plotted as a function of duration of deprivation, that is, the time from when the cataract was first diagnosed as dense and central until the cataract was removed surgically and the aphakic eye fitted with an appropriate contact lens. All but five children had Snellen acuities of at least $6 / 18$, regardless of the duration of deprivation and regardless of whether or not they had patched the normal eye. The five children with Snellen acuities worse than $6 / 18$ had all had long periods of deprivation (more than one year) beginning before 6 years of age.

Table 1 summarises the results and shows that the median acuity is influenced both by the duration and by the timing of deprivation. A comparison of the columns in Table 1 shows that Snellen acuity tended to be better in children who had had relatively short periods of deprivation (less than six months) than in children who had had longer periods of deprivation. A comparison of the rows in Table 1 shows that Snellen acuity tended to be better in children deprived after 3 years of age than in those deprived

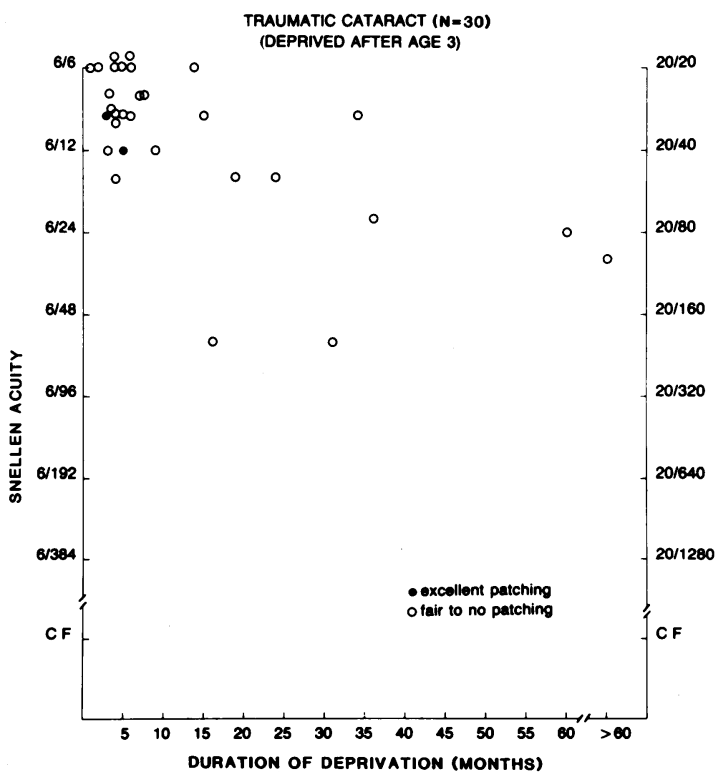

Fig. 2 Snellen acuity as a function of duration of deprivation in the aphakic eye of children treated for traumatic cataract. Other details as in Fig. 1. 
Table 1 Median acuity as a function of duration and timing of deprivation

\begin{tabular}{lll}
\hline & \multicolumn{1}{c}{ Duration of deprivation } \\
\cline { 2 - 3 } & $<6$ months $\geqslant 6$ months \\
\hline $\begin{array}{c}\text { Deprivation beginning from birth } \\
\text { (congenital cataract) }\end{array}$ & $6 / 15$ & $6 / 190$ \\
$\begin{array}{c}\text { Deprivation later } \\
\text { (traumatic cataract) }\end{array}$ & \\
$\begin{array}{c}\text { Beginning age } 3 \text { to 6 } \\
\text { Beginning after age } 6\end{array}$ & $6 / 10 \cdot 5$ & $6 / 24$ \\
& $6 / 7.5$ & $6 / 8$ \\
\hline
\end{tabular}

from birth. Moreover, there appears to be an interaction between duration and timing of deprivation such that the worst acuities were shown by children who had had long periods of deprivation beginning at birth. What is not illustrated in Table 1 is that the potentially poor outcome of early deprivation can be tempered by regular patching of the normal eye.

In summary, our results from tests of Snellen acuity show that visual deprivation during infancy does not prevent the development of good visual resolution, provided the deprivation is short and provided that, following the deprivation, the normal eye is patched regularly. Deprivation at a later age does not lead to the same deficiencies. These results are similar to those from monocularly deprived cats. $^{15}$

\section{Experiment II. Symmetry of optokinetic nystagmus}

A second aspect of vision measured in monocularly deprived children was the symmetry of optokinetic nystagmus. OKN is a series of jerky eye movements elicited by a repetitive pattern moving across the visual field. Thus the eyes follow a part of the pattern (slow phase) and then saccade back to pick up. another part (fast phase). In normal adult humans and cats $\mathrm{OKN}$ can be elicited easily both when stripes move from the temporal visual field toward the nasal field (for example, from right to left for the right eye) and when they move from the nasal visual field towards the temporal visual field (for example, from left to right for the right eye). ${ }^{12}{ }^{13}$ Thus their OKN is 'symmetrical'. In contrast, young human infants and kittens show consistent OKN when stripes move temporally to nasally but little or no OKN when stripes move in the opposite direction. ${ }^{689} 1416 \mathrm{We}$ refer to this difference in the ease of eliciting $O K N$ in the two directions as 'asymmetrical OKN'.

Like human newborn babies and kittens, cats which were monocularly deprived shortly after birth also show asymmetrical OKN. ${ }^{3417}$ Moreover, this asymmetry is present both in the previously deprived eye and in the non-deprived eye ${ }^{3417}$ (but see Malach et al. ${ }^{\circ}$ ). To determine whether deprivation affects similarly the symmetry of OKN in humans monocularly deprived from birth, we tested children treated for a dense unilateral congenital cataract (congenital group). For comparison, we also tested normal subjects and children who had had normal visual experience until they incurred a traumatic cataract sometime after 3 years of age (traumatic group).

\section{MATERIALS AND METHODS}

The congenital group consisted of 17 children who had had a dense central cataract diagnosed in one eye at a median age of 2 months (range birth to 6 months). The cataract had been removed surgically at a median age of 5.5 months (range 2 to 28 months) and the aphakic eye fitted with an appropriate contact lens at a median age of 9 months (range 3 to 29 months). At the time of the asymmetry test the children ranged in age from 1 to 13 years (median $=5$ years). Refractive errors ranged from $+2.0 \mathrm{D}$ to $+24.75 \mathrm{D}$ (median $=+16.5)$ in the aphakic eyes and from plano to $+3.0 \mathrm{D}$ (median= plano) in the normal eyes. For the eight children old enough to read an eye chart Snellen acuities ranged from 6/12 to merely light perception (median $=6 / 60$ ) in the aphakic eyes and from $6 / 6$ to $6 / 7 \cdot 5$ (median=6/6) in the normal eyes. We tested the normal eye of all 17 children but were able to test only six aphakic eyes primarily because of latent nystagmus in many cases.

The traumatic group consisted of 13 children who had incurred a dense cataract at a median age of 8.5 years (range 3 to 13 years). The cataracts had been removed surgically at a median age of 9 years (range 3 to 13 years), and the aphakic eyes had been fitted with an appropriate contact lens at a median age of 9 years (range 3 to 14 years). The median duration of deprivation was five months (range 1 to 34 months). At the time of the asymmetry test the median age of this group was 12 years (range 3 to 17 years). Their refractive errors ranged from $+10.5 \mathrm{D}$ to $+17.5 \mathrm{D}($ median $=+14.0 \mathrm{D})$ in the aphakic eye and from plano to $-1.0 \mathrm{D}$ (median= plano) in the normal eye. The 12 children old enough to read an eye chart had Snellen acuities ranging from $6 / 6$ to $6 / 30($ median $=6 / 12)$ in the aphakic eye and from $6 / 6$ to $6 / 9($ median $=6 / 6)$ in the normal eye. We tested the aphakic eye of all 13 children and the normal eye of eight.

The normal subjects $(n=26)$ ranged in age from 1 year to adulthood (median age $=4$ years). We tested the right eye of half the subjects and the left eye of the other half.

For the OKN test each subject had one eye occluded and sat $50 \mathrm{~cm}$ from a $90^{\circ} \times 90^{\circ}$ rear projection screen surrounded by black plywood. Black- 


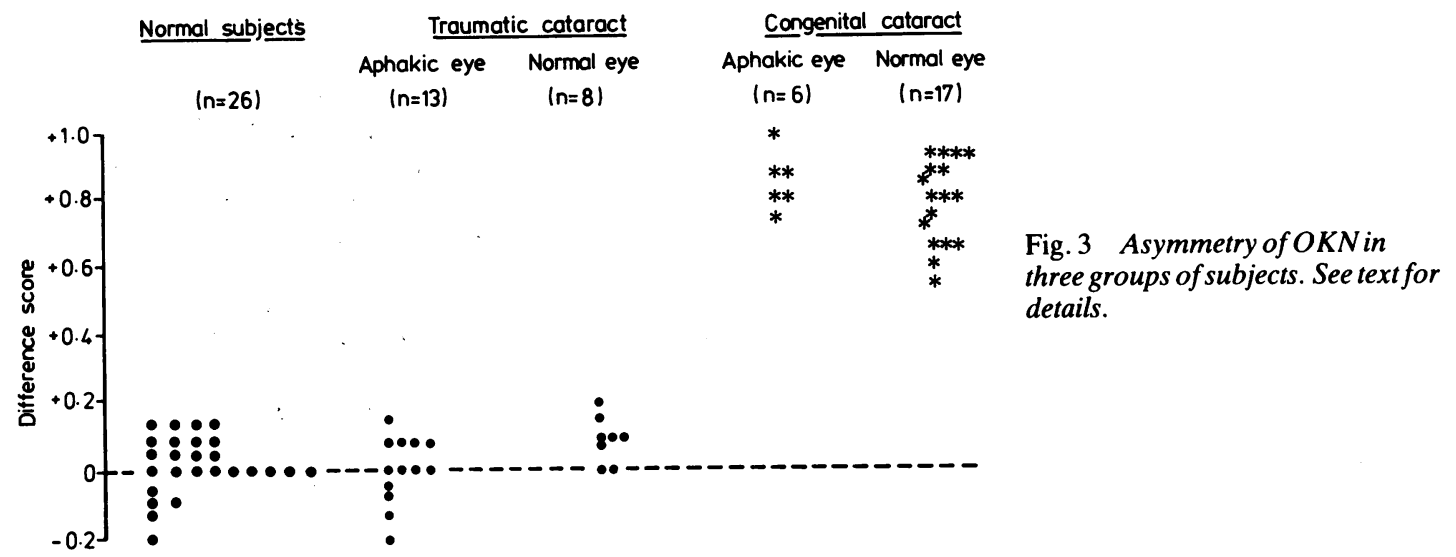

and-white vertical stripes $(0.6$ cycles $/ \mathrm{deg})$ were swept across the screen at a velocity of $13 \mathrm{deg} / \mathrm{s}$ by a $35 \mathrm{~mm}$ slide projector projecting through a rotating mirror. Shielded peepholes on either side of the screen permitted a clear view of the subject's unoccluded eye, but not of the stimuli. The test included 39 randomly ordered $7 \mathrm{~s}$ trials: 15 trials with stripes moving temporally to nasally, 15 trials with stripes moving nasally to temporally, and 9 control trials with a moving blank field. An observer decided during each trial whether OKN definitely occurred, possibly occurred, or definitely did not occur.

\section{RESULTS AND DISCUSSION}

The observer never reported definite OKN when the field was blank except during one trial for one subject.

For each eye, we used a two-tailed $\chi^{2}$ test to compare the frequency of trials on which OKN definitely occurred when stripes moved temporally to nasally versus the frequency when stripes moved nasally to temporally. Fig. 3 shows the difference between these two frequencies for each eye tested. A positive difference score means that definite OKN was observed on a greater proportion of trials when stripes moved temporally to nasally than when they moved nasally to temporally. Conversely, a negative difference score means that OKN was observed on a greater proportion of trials when stripes moved nasally to temporally than when they moved temporally to nasally. An asterisk indicates that a difference was significant by the $\chi^{2}$ test (that is, asymmetrical OKN) and a dot indicates that a difference was not significant (that is, symmetrical OKN).

In normal subjects and in both eyes of children treated for traumatic cataract definite OKN was observed on virtually every experimental trial. Thus their difference scores tended to cluster around zero, and in no case was there a significant asymmetry by the $\chi^{2}$ test (see Fig. 3). In contrast for the congenital group definite OKN was observed on most trials when stripes moved temporally to nasally but on few trials when stripes moved nasally to temporally. Thus in this group all the difference scores were positive and the asymmetry was significant by the $\chi^{2}$ test in every aphakic and normal eye tested. The magnitude of the asymmetry was not related to the duration of deprivation nor to the patching regimen. Children who had had early treatment and aggressive patching of the normal eye had asymmetries just as large as those who had had later treatment with little or no patching of the normal eye.

Factors other than early pattern deprivation per se might have contributed to the observed asymmetries. For example, asymmetrical OKN has been reported in subjects with amblyopia,,${ }^{1314}$ with esotropia,,${ }^{13} 1416$ or with reduced stereopsis for whatever reason. ${ }^{13}$ However, none of these factors was more common in children in the congenital group, all of whom showed asymmetrical OKN, than in children in the traumatic group, none of whom showed asymmetrical OKN.

Like our findings for visual resolution the timing of deprivation appears to affect the development of symmetrical OKN. Children deprived from birth showed a marked asymmetry of OKN, but those deprived after 3 years of age showed no such marked asymmetry. However, unlike visual resolution the symmetry of OKN appears to be unaffected by the duration of deprivation, at least when deprivation lasts between three and 29 months after birth or between one and 34 months after age 3 . Even short periods of deprivation early in life, which affect minimally the development of visual resolution, abolish the symmetry of OKN. Thus, as in animals, ${ }^{1}$ deprivation affects different visual functions during different critical periods.

\section{Experiment III. Peripheral vision}

Throughout the first six weeks of life kittens are less 
likely to orient towards objects in the nasal visual field (for example, the left visual field when looking with the right eye) than towards objects in the temporal visual field (for example, the right visual field when looking with the right eye). ${ }^{7}$ Recently we reported a similar pattern of results in young human infants shown lines of varying width located either at $30^{\circ}$ in the temporal visual field or at $20^{\circ}$ in the nasal visual field. "We assumed that, if infants could see a line, they would look towards it more often than they looked in the same direction on control trials when the field was blank. When lines were located at $30^{\circ}$ in the temporal visual field 1-month-old infants detected the narrowest line we presented, a line only $1.5^{\circ}$ wide. In contrast, when lines were located at $20^{\circ}$ in the nasal visual field, they detected a 'line' $25.6^{\circ}$ wide but showed no evidence of detecting a line even $12.8^{\circ}$ wide. Thus 1 -month-olds show at least an eightfold difference in the size of line they can detect at those locations. Normal adults on the other hand are better at detecting objects located at $20^{\circ}$ in the nasal visual field than objects located at $30^{\circ}$ in the temporal visual field. ${ }^{18}$

Cats which were monocularly deprived during a critical period shortly after birth, like young human infants and kittens, are especially poor at detecting stimuli in the nasal visual field of the deprived eye ${ }^{7}$ reviewed by Maurer and Lewis. ${ }^{2}$ To determine whether monocular deprivation has similar effects in humans we used the Goldmann perimeter to measure sensitivity along the horizontal meridian in one child treated for a unilateral congenital cataract. For comparison we also tested a child with no known eye disorders and children who had normal visual experience until they developed cataracts in one or both eyes.

\section{MATERIALS AND METHODS}

Two subjects, A and B, were tested extensively. Patient A was a 12-year-old child who had had a dense central cataract diagnosed in her left eye by 3 months of age. The cataract was removed at $4 \frac{1}{2}$ months and the aphakic eye fitted with a contact lens at 5 months. Subsequently her normal eye had been patched at least $50 \%$ of the waking time throughout early childhood, and at the time of the perimetry test she had 6/12 acuity in her aphakic eye and 6/6 acuity in her normal eye. Patient B was a 13-year-old child with 6/6 vision in each eye and no known eye problems. Five additional eyes from four children were tested less extensively by perimetry. All of these children had had normal visual experience and then developed dense, central cataracts in one eye or both eyes. Three of these patients had had developmental cataracts and one a traumatic cataract. Other details are listed in Table 3.
We used the Goldmann perimeter to test each eye of patient A with a 6.25 min spot of light (object I) and with a 13 min spot of light (object II) every $10^{\circ}$ along the horizontal meridian from 30 to $60^{\circ}$ in the temporal visual field, and from 10 to $60^{\circ}$ in the nasal visual field. For comparison we tested one eye of patient B with a 6.25 min spot of light at the same locations. The remaining subjects were tested only at $30^{\circ}$ in the temporal visual field and at $20^{\circ}$ in the nasal visual field. In each case the subject's task was to identify the one of two $2 \mathrm{~s}$ intervals during which a spot of light had appeared. At each location we used a staircase to determine the intensity at which the subject could identify the correct interval $75 \%$ of the time (PEST with $\mathrm{W}=1$, initial step size $=1 \log \mathrm{ml}$; final step size $=0.05 \log \mathrm{ml}) .{ }^{19}$

\section{RESULTS AND DISCUSSION}

The results for patients A and B are shown in Figs 4 (6.25 min spot) and 5 (13 min spot). At every location A required more intensity to detect light with her aphakic eye than with her normal eye, which gave results similar to those from the normal control

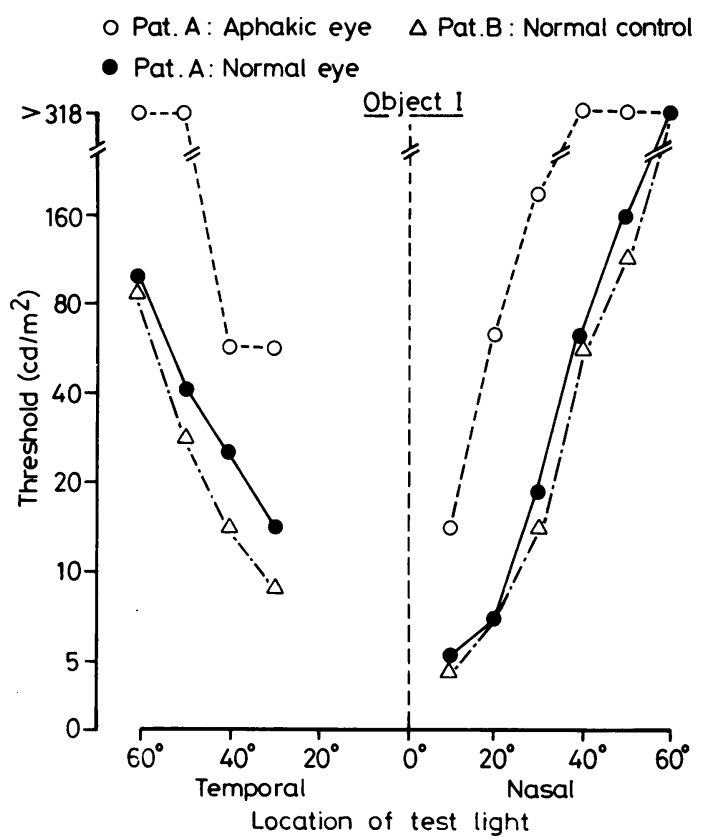

Fig. 4 The threshold luminance for detecting a $6 \cdot 25 \mathrm{~min}$ spot of light (object I) at various locations along the horizontal meridian for the aphakic and normal eyes of patient $A$, who was treated for a unilateral congenital cataract, and for one eye of patient $B$, who had no known eye disorders. We did not test $20^{\circ}$ in the temporal visual field because the blind spot interferes with the detection of small targets at that location. 


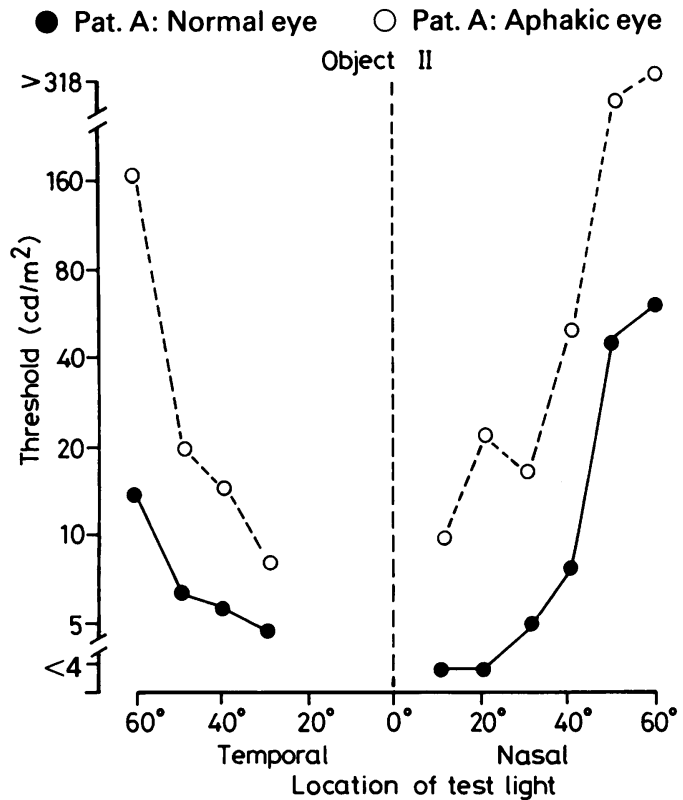

Fig. 5 The threshold luminance for detecting a 13 min spot of light (object II) at various locations along the horizontal meridian for the aphakic and normal eyes of patient $A$. Other details as in Fig. 4.

Table 2 Threshold intensities for patient $A$ (treated for unilateral congenital cataract) and $B$ (normal control subject) at $20^{\circ}$ in the nasal visual field and at $30^{\circ}$ in the temporal visual field

\begin{tabular}{lllcc}
\hline Subject & Condition & \multirow{2}{*}{$\begin{array}{l}\text { Object } \\
\text { size }\end{array}$} & \multicolumn{2}{c}{ Threshold $\left(\mathrm{cd} / \mathrm{m}^{2}\right)$} \\
\cline { 3 - 5 } & & & $20^{\circ}$ Nasal & $30^{\circ}$ Temporal \\
\hline A & Aphakic eye & I & $63 \cdot 5$ & $56 \cdot 6$ \\
& & II & $22 \cdot 5$ & $8 \cdot 5$ \\
A & Normal eye & I & $7 \cdot 1$ & $14 \cdot 2$ \\
& & II & $<4 \cdot 0$ & $4 \cdot 8$ \\
B & Normal & I & $7 \cdot 1$ & $9 \cdot 0$ \\
\hline
\end{tabular}

subject, $B$. Table 2 summarises the threshold intensities for patients $\mathrm{A}$ and $\mathrm{B}$ at $20^{\circ}$ in the nasal visual field and at $30^{\circ}$ in the temporal visual field, the locations we had tested in normal 1-month-olds." Like patient $B$ and like normal adults, ${ }^{18}$ A's normal eye had lower thresholds at $20^{\circ}$ in the nasal visual field than at $30^{\circ}$ in the temporal visual field. In contrast, unlike normal adults but like normal 1-month-olds, A's aphakic eye had higher thresholds at $20^{\circ}$ in the nasal visual field than at $30^{\circ}$ in the temporal visual field.

Table 3 lists thresholds for lights at those locations in the children who had had normal visual experience until they later developed cataracts. In every case threshold intensity at $20^{\circ}$ in the nasal field was equal to, or lower than, threshold intensity at $30^{\circ}$ in the temporal field. This pattern is like that of normal adults and very different from the pattern we observed in the aphakic eye of patient $A$, the child treated for a unilateral congenital cataract. It is evident that aphakia per se does not account for greater threshold elevation (that is, lower sensitivity) in the nasal as compared with the temporal field.

It is also unlikely that associated problems such as amblyopia or strabismus accounted for the results. Patient A had achieved 6/12 vision in her aphakic eye and showed especially poor detection in the nasal visual field, while one child in the control group (patient E) who had only 6/120 vision in her aphakic eye showed no such nasal field loss. Patient $A$ also had only a slight, variable tropia ( $4^{\Delta}$ esotropia to $6^{\Delta}$ exotropia at near; $6^{\Delta}$ to $8^{\Delta}$ of exotropia at far), and the literature suggests no consistent effect of strabismus on peripheral vision. ${ }^{20-22}$ It seems likely that our finding of especially poor detection in the nasal visual field of A's deprived eye is related at least in part to the visual deprivation caused by a congenital cataract. If that is the case, then early visual deprivation affects the development of humans' visual fields in much the same way it affects the

Table 3 Threshold intensities for subjects who developed cataracts after birth

\begin{tabular}{|c|c|c|c|c|c|c|c|c|}
\hline \multirow[t]{2}{*}{ Subject } & \multirow[t]{2}{*}{ Condition } & \multirow{2}{*}{$\begin{array}{l}\text { Age of } \\
\text { diagnosis } \\
\text { (months) }\end{array}$} & \multirow{2}{*}{$\begin{array}{l}\text { Duration of } \\
\text { deprivation } \\
\text { (months) }\end{array}$} & \multirow{2}{*}{$\begin{array}{l}\text { Age at } \\
\text { test } \\
\text { (years) }\end{array}$} & \multirow{2}{*}{$\begin{array}{l}\text { Snellen } \\
\text { acuity }\end{array}$} & \multirow{2}{*}{$\begin{array}{l}\text { Object } \\
\text { size }\end{array}$} & \multicolumn{2}{|c|}{ Threshold $\left(\mathrm{cd} / \mathrm{m}^{2}\right)$} \\
\hline & & & & & & & $20^{\circ} \mathrm{Nasal}$ & $30^{\circ}$ Temporal \\
\hline C & $\begin{array}{l}\text { Dev OD }{ }^{1} \\
\text { Dev OS }\end{array}$ & $\begin{array}{l}12 \\
7 \cdot 5\end{array}$ & $\begin{array}{l}5 \\
6 \cdot 5\end{array}$ & $\begin{array}{l}8 \cdot 5 \\
8 \cdot 5\end{array}$ & $\begin{array}{l}6 / 15 \\
6 / 12\end{array}$ & I & $\begin{array}{l}28 \cdot 4 \\
14 \cdot 2\end{array}$ & $\begin{array}{r}56 \cdot 6 \\
112.9\end{array}$ \\
\hline D & $\begin{array}{l}\text { Dev OD } \\
\text { Dev OS }\end{array}$ & $\begin{array}{l}17 \\
\text { Not tested }\end{array}$ & $\begin{array}{l}6 \\
\text { ause of second }\end{array}$ & $\begin{array}{c}7 \cdot 5 \\
\text { y membr }\end{array}$ & $6 / 9$ & III & $4 \cdot 5$ & $89 \cdot 7$ \\
\hline E & $\begin{array}{l}\text { Normal OD } \\
\text { Dev OS }\end{array}$ & $\begin{array}{l}\text { Not tested } \\
20\end{array}$ & 4 & 10 & $6 / 120$ & II & $28 \cdot 4$ & $35 \cdot 7$ \\
\hline $\mathbf{F}$ & $\begin{array}{l}\text { Traum OD } \\
\text { Normal OS }\end{array}$ & $\frac{145}{-}$ & 5 & $\begin{array}{l}13 \\
13\end{array}$ & $\begin{array}{l}6 / 7 \cdot 5 \\
6 / 6\end{array}$ & $\begin{array}{l}\text { II } \\
\text { II }\end{array}$ & $\begin{array}{r}5 \cdot 7 \\
<4 \cdot 0\end{array}$ & $\begin{array}{l}5 \cdot 7 \\
4 \cdot 5\end{array}$ \\
\hline
\end{tabular}

'Developmental cataract.

${ }^{2}$ Traumatic cataract. 
development of kittens' visual fields. In both cats and humans deprivation depresses sensitivity in the nasal visual field, so that, like the young human infant or the young kitten, the deprived eye is less sensitive to stimuli in the nasal field than at corresponding locations in the temporal field.

\section{Conclusions}

We have discussed three aspects of vision which are incompletely developed at birth in cats and in humans: visual resolution, the symmetry of OKN, and peripheral vision. In cats these abilities are adversely affected by monocular deprivation early in life. Thus after such deprivation visual resolution is reduced, $\mathrm{OKN}$ is asymmetrical, and cats fail to orient toward objects in the nasal visual field. After short periods of deprivation, some of these effects are reversible, especially if the normal eye is then sutured shut. Deprivation at a later age does not lead to the same deficiencies. Our results so far suggest that these same principles apply in humans who have been visually deprived in one eye during early infancy by the presence of a dense central cataract.

We thank Dr J Donald Morin, ophthalmologist-in-chief at the Hospital for Sick Children, for his encouragement and support. We also thank Adrienne Richardson, Cathy Holt, Donna Stewart, and Kelly Johnston for helping to collect and analyse the data. Special thanks go to the patients at the Hospital for Sick Children and to the normal subjects at McMaster University for volunteering their time.

This research was supported by grants from the National Eye Institute (NIH 5-R01-EYO-3475), from the Ontario Ministry of Health (PR 928), and from the Medical Research Council of Canada (MA-8894).

\section{References}

1 Mitchell DE. Sensitive periods in visual development. In: Aslin RN, Alberts JR, Petersen MR, eds. Development of perception: 2: The visual system. New York: Academic Press, 1981: 3-39.

2 Maurer D, Lewis TL. A physiological explanation of infants' early visual development. Can J Psychol 1979; 33: 232-52.

3 Van Hof-van Duin J. Early and permanent effects of monocular deprivation on pattern discrimination and visuomotor behaviour in cats. Brain Res 1976; 111: 261-76.

4 Van Hof-van Duin J. Development of visuomotor behavior in normal and light-deprived cats. In: Smith V, Keen J, eds. Clinics in developmental medicine. London: Spastics International Medical Publications. 1979; 73: 112-23.

5 Giffin F, Mitchell DE. The rate of recovery of vision after early monocular deprivation in kittens. J Physiol (Lond) 1978; 274: 511-37.

6 Malach R, Strong M, Van Sluyters RC. Analysis of monocular optokinetic nystagmus in normal and visually deprived kittens. Brain Res 1981; 210: 367-72.

7 Sireteanu R, Maurer D. The development of the kitten's visual field. Vision Res 1982; 22: 1105-11.

8 Van Hof-van Duin J. Direction preference of optokinetic responses in monocularly tested normal kittens and light deprived cats. Arch Ital Biol 1978; 116: 471-7.

9 Atkinson J. Development of optokinetic nystagmus in the human infant and monkey infant: an analogue to development in kittens. In: Freeman RD, ed. Developmental neurobiology of vision. New York: Plenum, 1979: 277-87.

10 Fantz R, Ordy J, Udelf M. Maturation of pattern vision in infants during the first six months. J Comp Physiol Psychol 1962; 55: 907-17.

11 Lewis TL, Maurer D, Blackburn K. The development of young infants' ability to detect stimuli in the nasal visual field. Vision Res 1985; 25: 943-50.

12 Braun JJ, Gault FP. Monocular and binocular control of horizontal optokinetic nystagmus in cats and rabbits. J Comp Physiol Psychol 1969; 69: 12-6.

13 Schor CM, Levi DM. Disturbances of small-field horizontal and vertical optokinetic nystagmus in amblyopia. Invest Ophthal Vis Sci 1980; 19: 668-83.

14 Atkinson J, Braddick O. Development of optokinetic nystagmus in infants: An indicator of cortical bionocularity? In: Fisher DF, Monty RA, Senders JW, eds. Eye movements: cognition and visual perception. Hillsdale, New Jersey: Erlbaum, 1981: 53-64.

15 Naegele J, Held R. The postnatal development of monocular optokinetic nystagmus in infants. Vision Res 1982; 22: 341-6.

16 Naegele JR, Held R. Development of optokinetic nystagmus and effects of abnormal visual experience during infancy. In: Jeannerod M, Hein A, eds. Spatially oriented behavior, New York: Springer, 1983: 155-74.

17 Hoffmann KP. Control of the optokinetic reflex by the nucleus of the optic tract in the cat. In: Hein A, Jeannerod M, eds. Spatially oriented behavior. New York: Springer, 1983: 135-53.

18 Frisén L, Glansholm A. Optical and neural resolution in peripheral vision. Invest Ophthal Vis Sci 1975; 14: 528-36.

19 Taylor M, Creelman C. PEST: efficient estimates on probability functions. J Acoust Soc Am 1967; 41: 782-7.

20 Duke-Elder S, Wybar K. System of Ophthalmology. Vol. 6. London: H Kimpton. 1973; 6: 313-4.

21 Feldman J, Taylor A. Obstacle to squint training-amblyopia. Arch Ophthalmol 1942; 27: 851-68.

22 Schmidt D, Reuscher A, Kommerell G. Über das nasale Gesichtsfeld bei Strabismus fixus divergens. Graefes Arch Klin Exp Ophthalmol 1971; 183: 97-104.

Accepted for publication 27 June 1985. 